Article

\title{
Forming Process, Microstructure, and Mechanical Properties of Thin-Walled 316L Stainless Steel Using Speed-Cold-Welding Additive Manufacturing
}

\author{
Wei Wu, Jiaxiang Xue *, Leilei Wang ${ }^{\circledR}$, Zhanhui Zhang ${ }^{\circledR}$, Yu Hu and Changwen Dong ${ }^{\circledR}$ \\ School of Mechanical and Automotive Engineering, South China University of Technology, 381 Wushan Road, \\ Tianhe District, Guangzhou 510641, China; 201710100398@mail.scut.edu.cn (W.W.); lleiwang@scut.edu.cn (L.W.); \\ 201610100399@mail.scut.edu.cn (Z.Z.); scshuyu@163.com (Y.H.); d.changwen@mail.scut.edu.cn (C.D.) \\ * Correspondence: mejiaxue@scut.edu.cn; Tel.: +86-020-2223-6360
}

Received: 22 November 2018; Accepted: 17 January 2019; Published: 21 January 2019

check for updates

\begin{abstract}
Wire and arc additive manufacturing (WAAM) produces thin-walled parts superior to other additive manufacturing methods, because of its high efficiency, good compactability, and low cost. However, the WAAM accuracy is limited by its large heat input. Here, $0.8 \mathrm{~mm} 316 \mathrm{~L}$ stainless steel welding wire is deposited via speed cold welding to form 30-layered thin-walled samples, with $2 \mathrm{~mm}$ thickness, and up to $65 \mathrm{~mm}$ height. The effects of three process parameters (the bottom current mode, scanning speed, and cooling time) on the deposition process stability, macro morphology, structure, and mechanical properties are studied. In the experiment, the probability density curves of electrical parameters of sample \#GRBC-30 cm $/ \mathrm{min}-10 \mathrm{~s}$ on the third and tenth layers were narrower than other samples, which implied a more stable process. The three process parameters mainly affect the deposition morphology and have a minor performance effect. The hardness and tensile properties mainly depend on the deposition direction. Gradual, layer-by-layer current reduction improves the bottom molding and performance, and the deposition efficiency, and stabilizes the process. Scanning speed enhancement or cooling time reduction destabilizes the end formation, reduces the effective deposition rate, and slightly degrades the performance. All deposited samples are distinctly anisotropic, but satisfy the industrial standard. Overall, deposition in speed cold welding mode, with $10 \mathrm{~s}$ cooling time, $30 \mathrm{~cm} / \mathrm{min}$ scanning speed, and gradually reduced bottom current exhibits good stability, and the molding efficiency and mechanical properties are optimal.
\end{abstract}

Keywords: speed cold welding; arc additive manufacturing; probability density; effective deposition rate; mechanical properties

\section{Introduction}

Compared with powder laser additive manufacturing, wire and arc additive manufacturing (WAAM) can reduce raw material wastage and has advantages of high molding efficiency, low cost, and easy commercialization [1,2]. For example, plasma arc additive manufacturing has been employed by Jhavar et al. [3] to produce AISI P20 steel samples exhibiting no cracks, pores, or inclusions on the micro level. Compared with gas tungsten arc welding and plasma arc augmentation, gas metal arc welding (GMAW) additive manufacturing with a wire feeder can facilitate manufacture and repair of large-scale and high-density components with high efficiency and low cost [4]. In addition, laser metal deposition of $0.8 \mathrm{~mm}$ AISI 316L stainless steel welding wire [5]; hence, 50 layers with a total height of $60 \mathrm{~mm}$ were deposited and excellent performance was achieved.

Although the WAAM method has the above advantages, its thermal input is relatively large, resulting in serious thermal accumulation that affects the molding precision and performance $[4,6]$. 
Furthermore, the process parameters directly affect the thermal input and thermal accumulation. Previously, Zhang et al. [7] performed a preliminary exploration of GMAW rapid formation, while Jiang et al. [8] studied the cold metal transition rapid forming method for 5356 aluminum alloy. In both studies, the experimental results showed that starting and ending the arc of each layer through back-and-forth scanning can reduce the possibility of melting collapse due to error and heat accumulation, thereby improving the forming efficiency and precision. Similarly, Xiong et al. $[9,10]$ adopted GMAW to study the forming characteristics and cladding size of arc additive manufacturing. They reported that lower interlay temperature yields superior molding appearance, and that higher wire feeding speed and scanning speed increase the surface roughness of the molding fittings. In addition, Yin et al. [11] studied the deposition process cooling time of 5356 aluminum alloy using tungsten inert gas (TIG), so as to control the heat input. A stable forming process was achieved when the cooling time between weld beads was two to five minutes, and good precision was obtained. Furthermore, the density of the deposited part increased with cooling time. In [6] and [12], GMAW additives were employed and the influence of cooling time on the surface roughness and height of H08Mn2Si alloy steel sedimentary samples was investigated. The above studies indicate that different technical parameters have certain effects on morphology in additive manufacturing.

In layer deposition, although the same parameters and welding methods are adopted for each layer, the morphology of the previous layer affects the arc stability of a subsequent layer and has a preheating effect on that layer. In particular, the molding and performance of the bottom layer differ from those of the layers above, because of the different heat dissipation characteristics of the substrate. Previously, Wu et al. [13] and Martina et al. [14] performed WAAM on titanium alloy. As a result of the cooling influence of the substrate, the first four molded layers were unstable; thus, the bottom was removed when the effective deposition area was measured in those works. Furthermore, in [15-18], substrate materials different from the welding wires were used, which involved TIG additive manufacturing of ferroaluminum alloy [15], plasma arc carbon steel deposition [16,17], and laser arc hybrid deposition of AISI 301 [18]. As elements in the substrate may have been mixed in the bottom layer and influenced the material performance, the sample bottoms were removed. However, this approach yields material waste and reduces the effective deposition rate.

As noted above, a newly deposited layer has the effect of repeated heating on a previously deposited layer, and the mutual influence between the previous and subsequent layers complicates the deposition process. Therefore, it is necessary to investigate the influence of the process parameters (welding current, arc voltage, etc.) on the deposition process stability. The voltage and current waveforms of four arc modes (cold metal transfer (CMT), CMT pulse, CMT advanced, and CMT pulse advanced) applied to Al-Cu alloy were reported previously [19], and the local voltage and current waveforms of a certain layer in the CMT WAAM process were investigated for aluminum alloy $[20,21]$. Furthermore, Li et al. [22] examined the relationship between droplet transition frequency and voltage by using a piezoelectric sensor to detect the current waveform; hence, the influence of the droplet transition frequency on the deposition stability was determined. However, in the above studies, the multi-layer electric quantity of the additive manufacturing process was not studied. This is despite the fact that the voltage and current waveforms of the different layers produced in the deposition process reflect the variation and stability of that process.

In this study, a speed cold welding mode with relatively small thermal input is applied to perform reciprocating metal inert gas (MIG) welding deposition using 316 L stainless steel wire with a diameter of $0.8 \mathrm{~mm}$. The voltage and current signals of the deposition process are recorded and the probability densities are calculated. The stability of the deposition process is analyzed by changing three process parameters (the bottom current mode [23]; i.e., the current reduction mode of the first eight layers; the cooling time, and the speed). The influence of the technical parameters on the shaping is analyzed by comparing the shapes and effective deposition rates of the deposited samples. The microstructures and mechanical properties of the sedimentary samples are studied to determine the effects of the process parameters. 


\section{Materials and Methods}

\subsection{Test Materials and Equipment}

316L stainless steel welding wire with $0.8 \mathrm{~mm}$ diameter and a $250 \mathrm{~mm} \times 100 \mathrm{~mm} \times 5 \mathrm{~mm}$ base plate were selected for the test. The welding wire composition is presented in Table 1. Before the test, the substrate surface was polished, before being cleaned with acetone and blown dry. The MIG welding additive manufacturing system used in the test is shown in Figure 1. The system consisted of a Lorch S3 Robot MIG XT welding power supply (LORCH, Auenwald, Germany), a Fanuc M-10ia six-axis robot (FANUC, Yamanashi Prefecture, Japan) and R-30iB robot control cabinet (FANUC, Yamanashi Prefecture, Japan), a Hall voltage and current sensor (Hall-Effect sensor, Nanjing Qiangneng Sensor Technology Co., Ltd, Nanjing, China), a National Instruments data acquisition system (National Instruments, Austin, TX, USA), and a PC.

Table 1. Chemical composition of 316L wire (mass fraction \%).

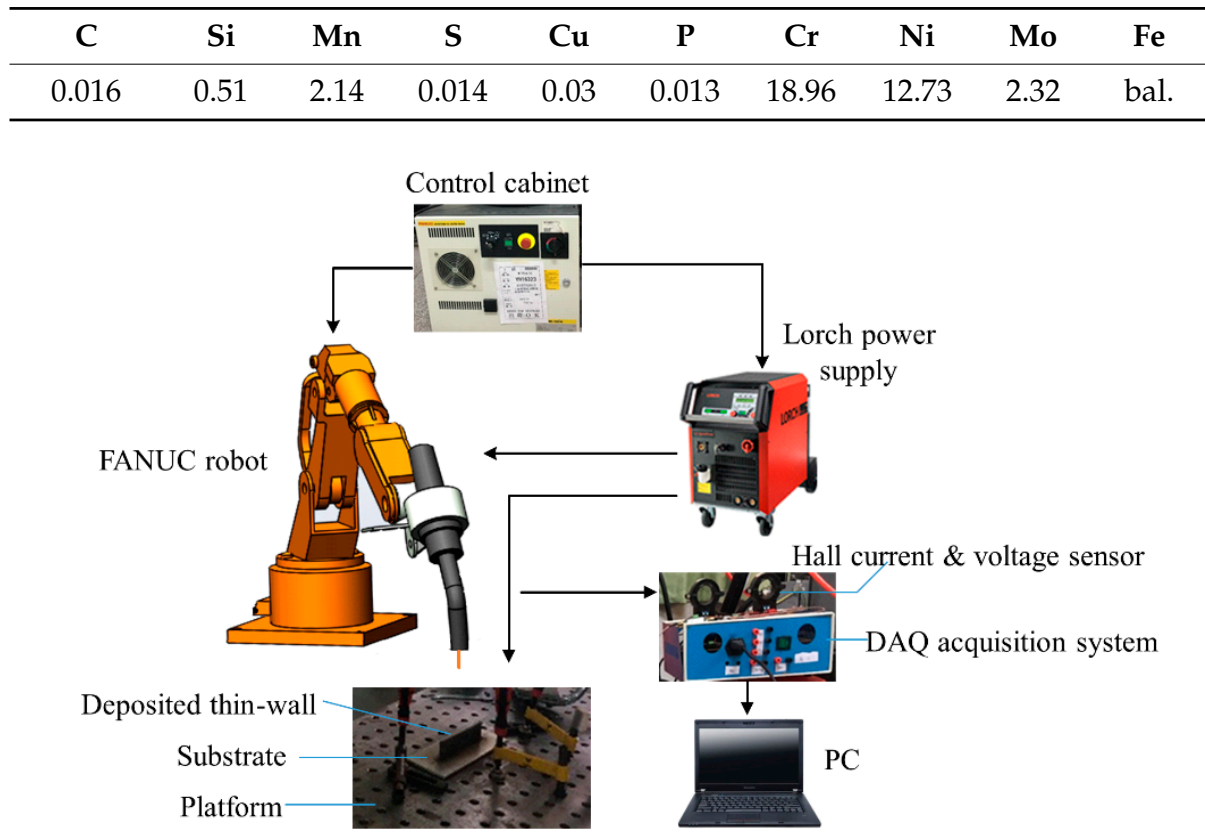

Figure 1. Schematic of MIG (metal inert gas) additive manufacturing equipment.

\subsection{Experiment Conditions}

In pre-testing, it was noted that the surfaces of the first two layers could not be melted easily through small-current welding, and that this affected the subsequent deposition. Therefore, to increase the thermal input of the first two layers, it was necessary to increase the current to $100 \mathrm{~A}$; that for the latter layers was set to $60 \mathrm{~A}$. The scanning speed was $25-35 \mathrm{~cm} / \mathrm{min}$. The shielding gas was $99.999 \%$ highly pure argon and the gas flow was $20 \mathrm{~L} / \mathrm{min}$. The electrode extension was $12 \mathrm{~mm}$ and the system could self-regulate the arc length. A reciprocating-type method [9] was adopted to perform 30 layers of surfacing in this experiment. Following completion of a $150 \mathrm{~mm}$ long weld on each layer, the welding torch was raised by $2.0 \mathrm{~mm}$ (for the first two layers, it was raised by $1.8 \mathrm{~mm}$ ) and the next layer was deposited. This process was repeated until the additive manufacturing process was complete.

The speed cold welding method was used in single-pass and multi-layer forming tests, and a single variable was considered in each part of the experiment. That is, the influence of the welding current, scanning speed, and interlayer cooling time employed during the additive manufacturing process on the stability, the formed part appearance, and the microstructures and mechanical properties were investigated. The welding parameters are listed in Table 2 (note that the welding voltage and wire feeding speed were automatically matched by the intelligent welding 
machine). A total of six samples were considered. Through parameter adjustment, the effects of gradual and transient currents between the bottom layers were studied, based on comparison of samples \#TRBC (TRBC means transient reduction of bottom current) and \#GRBC-30 cm/min-10 s (GRBC means gradual reduction of bottom current). When the scanning speed was reduced to 25 $\mathrm{cm} / \mathrm{min}$ and the relative wire feeding rate was too small, then the deposition process was terminated without completion. Therefore, the impact of the scanning speed on the molding and performance was studied using samples \#GRBC-30 cm/min-10 s and \#35 cm/min. As heat accumulation occurred during the reciprocate walking of the WAAM process, samples $\# 0 \mathrm{~s}$, \#5 s, \#GRBC-30 cm/min-10 s, and \#15 s were compared to study the impact of different cooling times on molding and performance.

Table 2. Arc deposition experiment parameters (TRBC and GRBC represent transient and gradual reduction of bottom current, respectively).

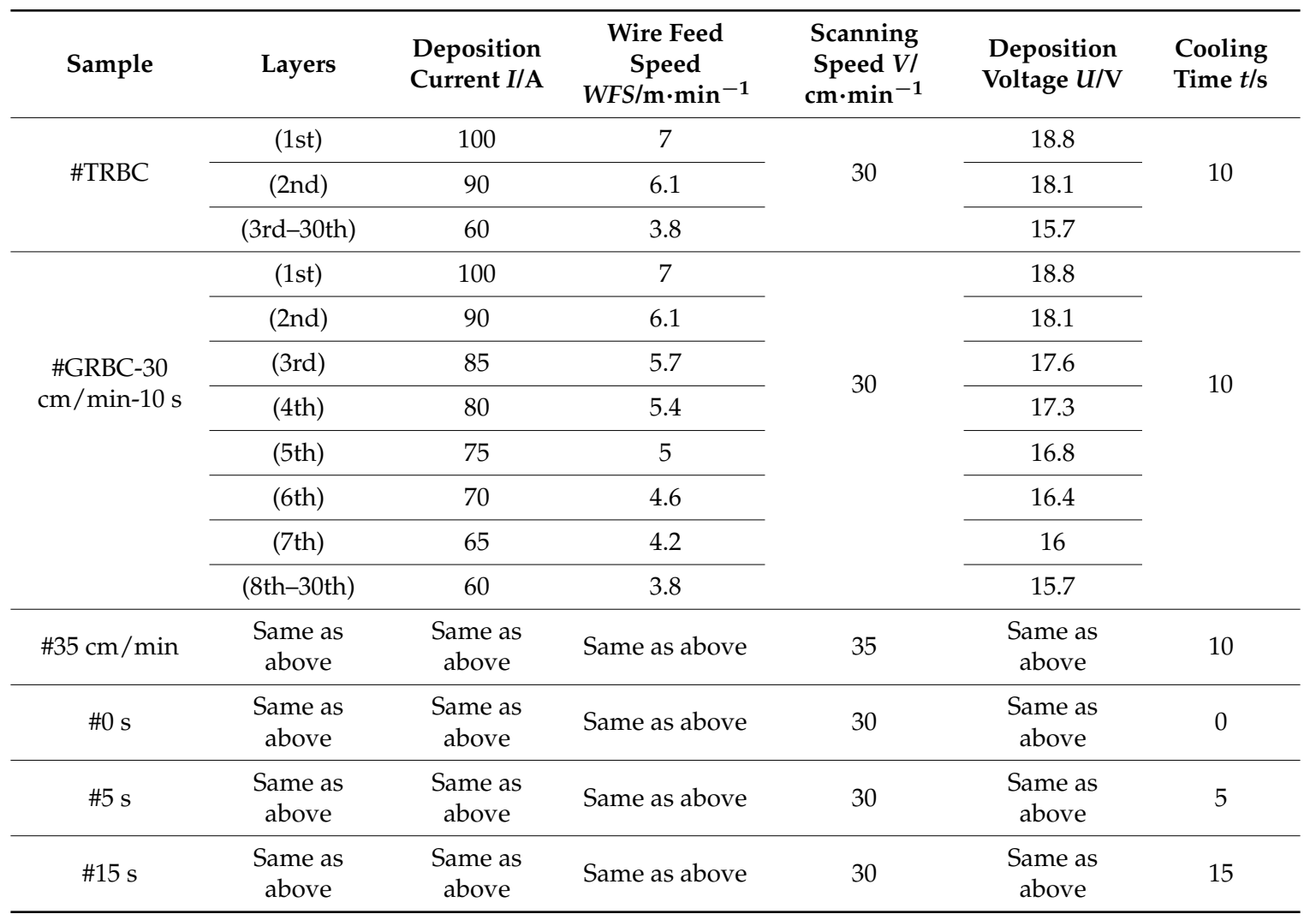

After the surfacing welding, sanders were used to grind out the oxide surface and a wire cutting machine was used to sever $15 \mathrm{~mm}$ segments from both sample ends [19]. Thus, a length of $120 \mathrm{~mm}$ in the middle of the original sample remained as the effective deposition area. To avoid large error, the most central stable part near the vertical wall body was selected, and transverse and longitudinal sections with $10 \mathrm{~mm}$ width were cut to prepare wall microstructure and hardness samples, as shown in Figure 2a. The greasy dirt on the surface of each metallographic sample was wiped away using acetone, and the sample was inlaid through a cold inlay process. First, 180\#,600\#, and 800\# sandpapers were used for rough grinding. Then, 1200\#, 2500\#, and 5000\# sandpapers were used for fine grinding, followed by polishing with a $2.5-\mu \mathrm{m}$-particle diamond polishing agent. Finally, the metallographic samples were corroded using aqua regia $\left(\mathrm{HCl}: \mathrm{HNO}_{3}=3: 1\right)$ for $30 \mathrm{~s}$, before being rinsed and dried with water and alcohol, respectively. The microstructural characteristics of the depositions were analyzed with an optical metallographic microscope (Leica Microsystems Ltd, Solms, Germany) and the microhardness in the deposited direction was tested with an HMV-2T micro Vickers hardness tester (SHIMADZU Ltd, Kyoto, Japan). A load of $0.5 \mathrm{~kg}$ was maintained for $10 \mathrm{~s}$ during the test. At the metallographic cross-section, 20 points were tested on each of the upper (layers 26-30), middle 
(layers 13-17), and lower (layers 1-4) parts, with the points being separated by $0.5 \mathrm{~mm}$ intervals in the deposition direction. Then, the average hardness values of the upper, middle, and lower parts were calculated and compared.

Because reciprocating additive manufacturing was employed, the difference between the left and right ends at the thin wall was not obvious. Three horizontal stretch samples labeled H1-H3 were extracted from the upper, lower, and bottom left side, respectively, and three vertical stretch samples labeled V1-V3 were extracted from the right side. The sampling method is shown in Figure 2a. The average value of six samples selected from different parts of the deposition (upper and lower, left and right) could represent the stretching result of the whole material. The tensile samples designed in the test were smaller than the minimum size of the international standard sample. Therefore, all tensile sample sizes were reduced in proportion to the international standard; the tensile sample size is shown in Figure 2b. Although the width of the tensile sample was $3 \mathrm{~mm}$, one horizontal specimen contained 1.5 to 2 layers, approximately, for the difference in layer height (according to average height per layer in Table 3), which could include inner layer and interlayer. An electronic universal testing machine CMT5105 (Shenzhen New Sanxin material testing Co., Ltd., Shenzhen, China) was used with a maximum load of $100 \mathrm{kN}$. In accordance with the GB/T 228-2002 standard, tensile tests were conducted parallel and perpendicular to the welding scanning direction at a speed of $2 \mathrm{~mm} / \mathrm{min}$ at room temperature. Stretch samples were taken from the substrate for comparative analysis. The horizontal and vertical yields and tensile strengths of the tensile specimens were averaged to avoid the test contingency and error. A FEI Quanta 200 scanning electron microscope (SEM) (FEI, Hillsboro, USA) was used to observe the fracture morphologies of snapped samples.

Table 3. $V_{\text {total }}, V_{\text {effective, }}$ DR, EDRM, and DT values calculated for depositions (TRBC and GRBC represent transient and gradual reduction of bottom current, respectively).

\begin{tabular}{ccccccc}
\hline Sample & $\begin{array}{c}\mathbf{V}_{\text {total }} \\
\left.\mathbf{( c m}^{3}\right)\end{array}$ & $\begin{array}{c}\mathbf{V}_{\text {effective }} \\
\left.\mathbf{c m}^{3}\right)\end{array}$ & $\begin{array}{c}\text { DR } \\
\mathbf{( \% )}\end{array}$ & $\begin{array}{c}E D R M \\
(\% / m i n)\end{array}$ & $\begin{array}{c}\text { DT } \\
(\mathbf{m i n})\end{array}$ & $\begin{array}{c}\text { Average Height } \\
\text { Per Layer (mm) }\end{array}$ \\
\hline \#TRBC & 30.028 & 12.307 & $40.985 \%$ & 2.006 & 20.43 & 2.17 \\
\hline $\begin{array}{c}\# \mathrm{GRBC}-30 \\
\mathrm{~cm} / \mathrm{min}-10 \mathrm{~s}\end{array}$ & 31.511 & 16.90 & $53.62 \%$ & 2.625 & 20.43 & 2.167 \\
\hline$\# 35 \mathrm{~cm} / \mathrm{min}$ & 27.01 & 14.40 & $53.3 \%$ & 2.915 & 18.283 & 2.03 \\
\hline$\# 5 \mathrm{~s}$ & 31.511 & 16.70 & $52.99 \%$ & 2.94 & 18.017 & 2.13 \\
\hline$\# 15 \mathrm{~s}$ & 31.511 & 14.73 & $46.74 \%$ & 2.045 & 22.85 & 2.18 \\
\hline
\end{tabular}

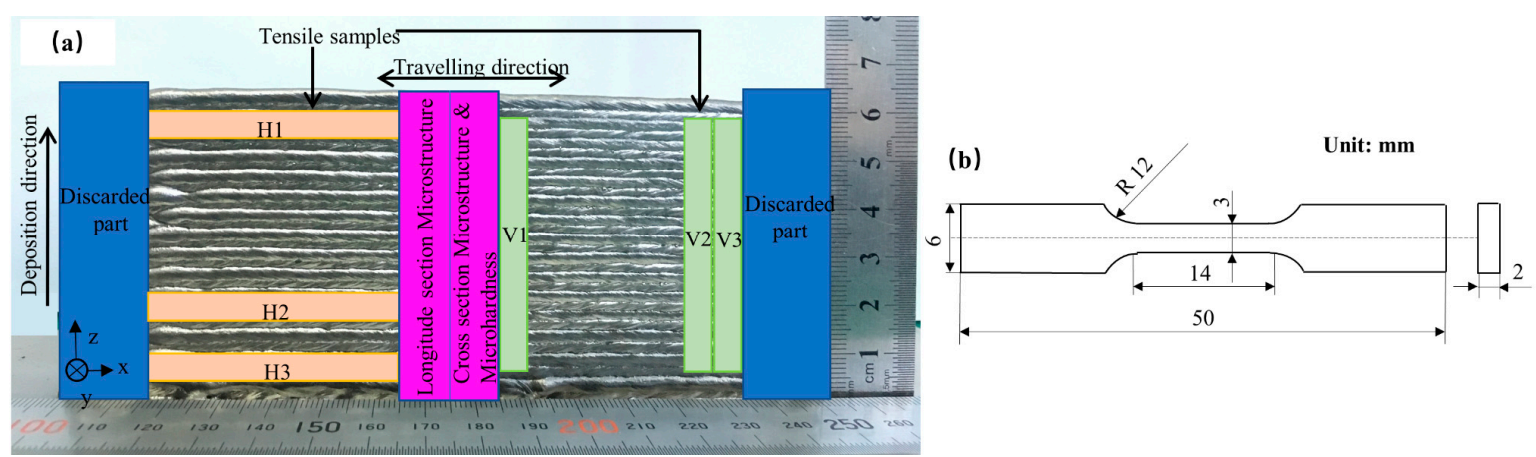

Figure 2. (a) Extraction locations on each wall to obtain microstructure, microhardness, and tensile samples; (b) tensile specimen dimensions. 


\section{Results and Discussion}

\subsection{Waveform Analysis}

The transient voltage and current signals were collected and filtered by the data acquisition card (NI-USB6363, National Instruments, Austin, USA) and LabVIEW software (LabVIEW2014, National Instruments, Austin, USA). The intermediate $20 \mathrm{~s}$ waveform was analyzed in each layer and the average current and voltage values were calculated. The current mode of sample \#TRBC was 100-90-60-60 A; therefore, only the current and voltage waveforms of the first four layers were collected. For samples \#GRBC-30 cm/min-10 s, \#35 cm/min, \#5 s, and \#15 s, the waveforms of the first ten layers were collected and analyzed. The average current and voltage values, and the probability density of each layer were then calculated and the deposition process stability was analyzed. Hence, real-time online detection of the voltage and current waveforms, and stability analysis of additive manufacturing was realized.

In Figure 3a, the average current and voltage values of each sample fluctuate around the preset value. This behavior indicates that the bottom current mode, cooling time, and scanning speed had little influence on the average voltage and current. (The values for the 3rd and 4th layers of sample \#TRBC were preset to $60 \mathrm{~A}$; thus, those curves do not overlap the other curves in the figure). Figure $3 \mathrm{~b}$ shows the voltage and current envelope curves of the 7 th layer of sample \#GRBC-30 cm/min-10 s at 12.5-13.5 s; good waveform stability is apparent. Figure 3c shows a magnified view of the curves in Figure 3b, from 12.8-13 s. It is clearly apparent that the current and voltage waveforms exhibit certain periodicity. As the speed cold mode is an improved short-circuit transition mode with internal current control, the current is not excessively high in the short-circuit stage and the droplet spatter is reduced.
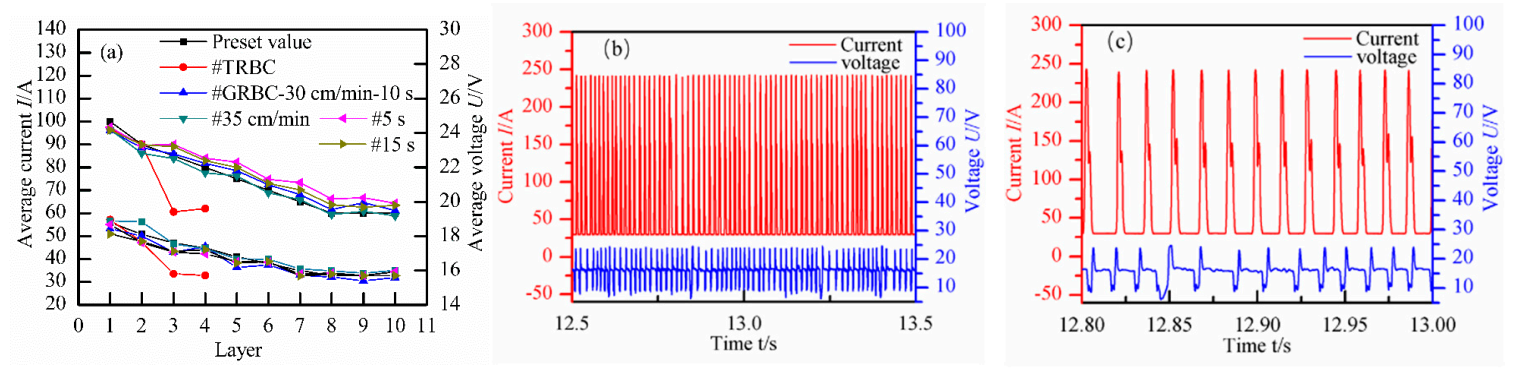

Figure 3. Current and voltage waveforms of additively manufactured walls: (a) Comparison of average currents and voltages for different samples and preset values; (b) partial current and voltage waveforms of the 7 th layer of sample \#GRBC-30 cm/min-10 s; (c) enlarged current and voltage waveforms from 12.8 to $13 \mathrm{~s}$ in (b). (TRBC and GRBC represent transient and gradual reduction of bottom current, respectively).

The voltage and current probability densities were determined through post-processing of the electrical signals recorded during the process, which can reflect the welding process stability. Under the same welding conditions, a narrower probability density curve indicates more concentrated current and arc voltage distributions. Furthermore, a smaller fluctuation range corresponds to greater arc stability [24,25] (i.e., a higher-stability deposition process in the same layer). As a result of the similarities between the waveforms of samples \#15 s and \#GRBC-30 cm/min-10 s (i.e., the probability density curves for $10 \mathrm{~s}$ and $15 \mathrm{~s}$ cooling are quite similar), comparative analysis of sample \#15 s was not performed. The voltage and current probability densities of the 3rd layers of all samples were tested to study the influences of transient and gradually reduced currents on the arc stability, as shown in Figure $\left.4 \mathrm{a}_{1}, \mathrm{~b}_{1}\right)$. Note that the ordinates of the probability density curves are indicated using logarithmic coordinates to enlarge the unstable region for comparison. The higher and narrower the entire shadow area of the probability density curve, the more concentrated the current and voltage values, and the more stable the process. As shown in Figure $4 a_{1}$, the areas of the sample \#TRBC and \#5 s curves are relatively wide and narrow, respectively, but dispersion values are apparent at the locations with small 
current. The area of the sample $\# 35 \mathrm{~cm} / \mathrm{min}$ curve is relatively wide and the fluctuations at the large current locations are large.
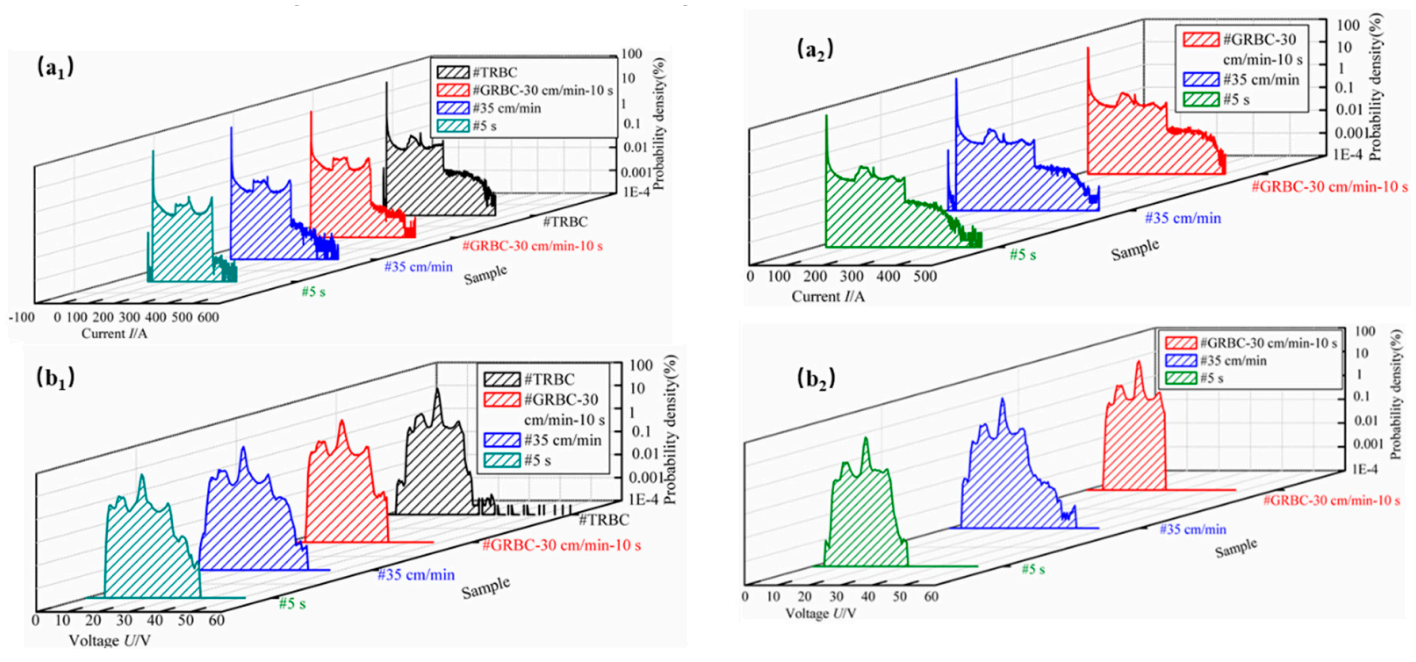

Figure 4. Comparison of probability density distributions of different layers and different samples: (a) Current probability densities $\left(\mathbf{a}_{\mathbf{1}}\right)$ on the 3rd layer of samples \#TRBC, \#GRBC-30 cm/min-10 s, $\# 35 \mathrm{~cm} / \mathrm{min}$, and \#5 s, and $\left(\mathbf{a}_{2}\right)$ on the 10th layer of samples \#GRBC-30 cm/min-10 s, \#35 cm/min, and \#5 s; (b) voltage probability densities $\left(\mathbf{b}_{\mathbf{1}}\right)$ on the $3 \mathrm{rd}$ layer of samples \#TRBC, \#GRBC-30 cm $/ \mathrm{min}-10 \mathrm{~s}$, $\# 35 \mathrm{~cm} / \mathrm{min}$, and \#5 $\mathrm{s}$ and $\left(\mathbf{b}_{\mathbf{2}}\right)$ on the 10th layer of samples \#GRBC-30 cm/min-10 s, \#35 cm/min, and \#5 s. (TRBC and GRBC represent transient and gradual reduction of bottom current, respectively).

The differences in the voltage probability densities can better indicate the arc voltage stability, (i.e., the deposition process stability). In Figure $4 b_{1}$, the curves for samples \#35 cm/min and \#GRBC-30 $\mathrm{cm} / \mathrm{min}-10 \mathrm{~s}$ have the widest and narrowest areas, respectively, while the result for sample \#TRBC indicates more dispersion values for the high voltage value. This behavior was due to transient currents that destabilized the arc. Thus, the 3rd layer of sample \#GRBC-30 cm/min-10 s (gradual reduction of bottom current) was more stable. Comparisons of the current and voltage probability density curves of the 10th layers of each sample are shown in Figure $4 a_{2}, b_{2}$, respectively. In these figures, the sample \#GRBC-30 cm/min-10 s curves are narrow and high, and the area of the sample \#35 cm/min curves are relatively wide, and dispersion values are apparent under small current. These results indicate that, as the speed increased, a higher layer corresponded to poorer voltage and current stability. However, 5 s cooling (sample \#5 s) rendered the interlayer heat accumulation more serious than that obtained for the $10 \mathrm{~s}$ cooling of sample \#GRBC-30 cm/min-10 s, and the inter-layer arc stability was poor. Therefore, based on analysis of the voltage and current wave stability, gradual current reduction and speed with $30 \mathrm{~cm} / \mathrm{min}$ and $10 \mathrm{~s}$ cooling are optimal process parameters.

\subsection{Macro Morphologies of Deposited Samples}

The morphologies of different parts of the depositions are shown in Figure 5. These samples had a good appearance overall, with no obvious defects between layers. Figure 5a shows an oblique view of sample \#GRBC-30 cm/min-10 s, with a thin and high forming part. The layer height was uniform, and the deposition height was as shown in Figure 6a, having the potential to reach approximately $65 \mathrm{~mm}$. Note that this height exceeds the deposition height (approximately $60 \mathrm{~mm}$ ) of the 50 layers obtained using $0.8 \mathrm{~mm}$ 316L stainless steel by laser metal depostion reported in the literature [5]. Thus, the process efficiency was relatively high. 

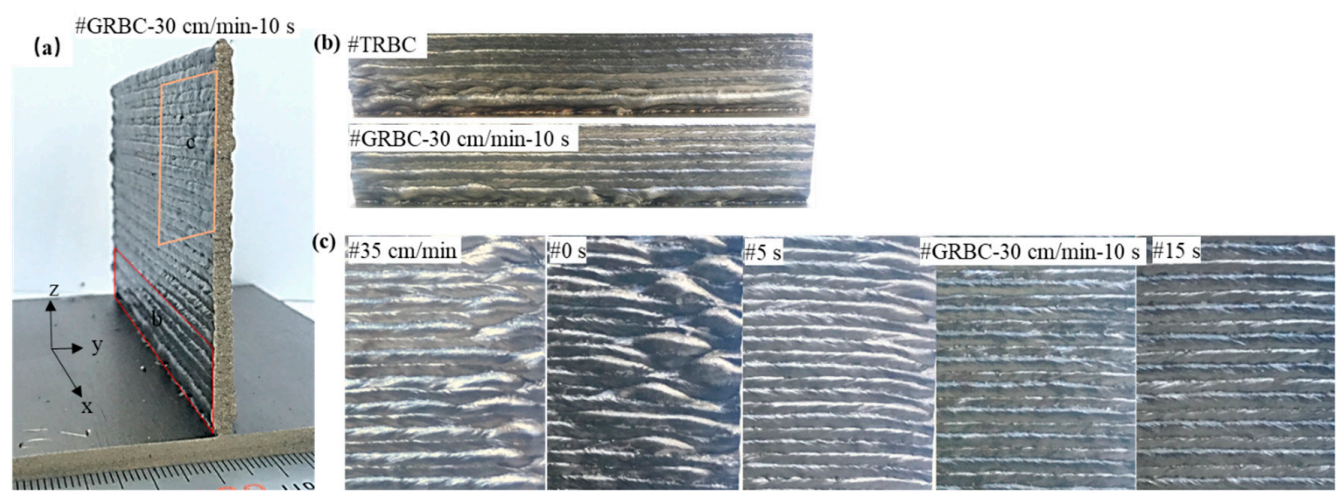

Figure 5. Profile morphologies of deposited wall samples prepared using different parameters: (a) Sample \#GRBC-30 cm/min-10 s profile; (b,c) bottom and top-right parts of different samples, respectively (the parts in (b) correspond to the bottom region of (a), whereas the parts in (c) correspond to the top-right region of (a)). (TRBC and GRBC represent transient and gradual reduction of bottom current, respectively).
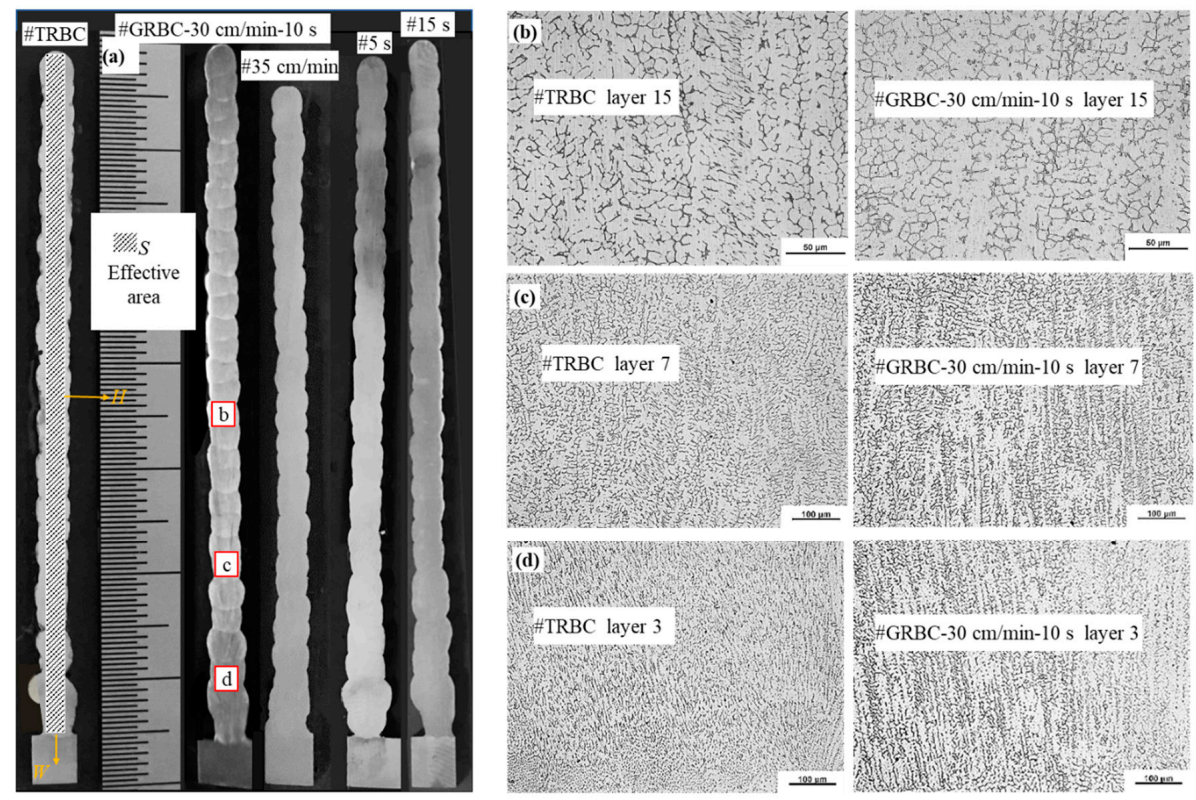

Figure 6. Macrographs and microstructures of transverse cross-sections of sample midsections: (a) Macrographs of transverse cross-sections of sample midsections; microstructures of samples \#TRBC and \#GRBC-30 cm/min-10 s, (b) on the 15th layer, (c) on the 7th layer, and (d) on the 3rd layer. (TRBC and GRBC represent transient and gradual reduction of bottom current, respectively).

Figure $5 \mathrm{~b}$ shows the bottom areas of samples \#TRBC and \#GRBC-30 cm/min-10 s, and mainly compares the effects of transient and gradual current reduction on the bottom morphology. It is apparent that samples \#TRBC and \#GRBC-30 cm/min-10 s become stable beginning from the 6 th and 3rd layers, respectively. Thus, gradual current reduction yields suitable bottom formation and improves the effective deposition rate.

The heat dissipation condition of reciprocating accumulation is poor, being worse at both part ends than in the center. Therefore, by considering the end formation (without considering the arc initation and termination), the influence of the process parameters on the specimen shaping was studied. Figure $5 \mathrm{c}$ shows the upper-right region of the sample in Figure $5 \mathrm{a}$. Here, samples \#35 cm $/ \mathrm{min}$ and \#GRBC-30 cm/min-10 s were used to compare the impact of the scanning speed parameters on the forming. As a result of the speed increase for sample $\# 35 \mathrm{~cm} / \mathrm{min}$, the melting cladding rate of each layer was reduced, especially in relation to the unevenness of both ends caused by the arc initiation 
and termination. The unevenness accumulated as a result of the reduced melting. Although its energy input was reduced, the local heat dissipation time within the same layer was reduced, yielding mixed layers and poor forming. The effect of the cooling time on the forming was compared by considering samples \#0 s, \#5 s, \#GRBC-30 cm/min-10 s, and \#15 s. Continuous additive manufacturing was applied for sample \#0 s. As the arc of the entire process was not interrupted for this sample, the deposited layers eventually collapsed as a result of the excessively high temperature. This is especially true for both ends of the path, where the arc remained for a long period of time and the heat dissipation condition was relatively poor. In that case, the excessive residual heat superheated the molten pool. As it is difficult for the heat of a molten pool to dissipate in time, the fluidity of the molten pool was enhanced, and mixed layers appeared after solidification. Thus, a certain cooling time is required [9]. The cooling time of sample \#5 s improved morphology compared with sample \#0 s; however, collapse of both ends still occurred and the influence of the thermal accumulation remained. However, when the cooling time was set to 10 or $15 \mathrm{~s}$, the end formation improved and was almost independent of the thermal accumulation. Therefore, considering the material additive efficiency, the parameters employed for sample \#GRBC-30 cm/min-10 s are optimal.

As a result of the different process parameters, the deposited samples had different roughnesses and heights. As it is necessary to remove the irregular parts of a final processed sample, the utilization efficiency should be considered. The macroscopic cross-sections of the samples obtained in this study are shown in Figure 6a. No macroscopic defects such as visible pores, cracks, and unfused layers are visible in the depositions. Furthermore, the interlayer metal is well connected. As a result of the stable deposition process, the intervals between layers are clearly visible.

To compare the deposition efficiencies obtained for the different parameters, the sample lengths after excision were kept the same. The effective height and width $[3,14,26]$ of the cross-section in the center of each sample were measured, as shown in Figure 6a. The effective area of the cross-section of the deposited sample (e.g., the shaded part of sample \#TRBC in Figure 6a) could be determined, and the effective deposition volume ( $\left.V_{\text {effective }}\right)$ was calculated using Equation (1):

$$
V_{\text {effective }}=S \times L=W \times H \times L,
$$

here, $S, W$, and $H$ represent the effective area, width, and height of the cross-section of the deposited sample, respectively, as apparent from Figure 6a. Furthermore, $L=12 \mathrm{~cm}$ is the sample effective length.

In the speed cold mode, the total set time of arc initiation and termination were $1.2 \mathrm{~s}$ and the wire feeding speed was $1 \mathrm{~m} / \mathrm{min}$. The total deposited volume $\left(V_{\text {total }}\right)$ could be calculated from the wire feed quantity, as shown by Equation (2):

$$
V_{\text {total }}=\sum_{1}^{30}(W F S \times T) \times \pi \times r^{2},
$$

where WFS and $T$ are, respectively, the wire feeding speed and scanning time of each layer, which is determined by the total length and scanning speed. Here, $r=0.4 \mathrm{~mm}$ is the wire radius. The formula for calculating the effective deposition rate $(D R)$ is as follows:

$$
D R(\%)=\frac{V_{\text {effective }}}{V_{\text {total }}} \times 100 \%
$$

As regards the effect of time on efficiency, the total deposition time (DT) includes the scanning time for each layer, the wait time between layers, and the period of arc initiation and termination. Thus, the effective deposition rate per unit time (i.e., per minute) (EDRM) was calculated from Equation (4):

$$
\operatorname{EDRM}(\% / \mathrm{min})=\frac{D R}{D T}
$$


The calculation results obtained using the above equations are presented in Table 3. Ignoring the spatter generated during deposition, the EDRM values for samples $\# 35 \mathrm{~cm} / \mathrm{min}$ and $\# 5 \mathrm{~s}$ were the largest. However, mixed layer flow occurred for samples $\# 35 \mathrm{~cm} / \mathrm{min}$ and $\# 5 \mathrm{~s}$ due to the uneven forming of both ends, as shown in Figure 5c. Thus, the actual $V_{\text {effective }}$ was smaller and the efficiency was lower; these findings are consistent with results reported in [11], in which it was concluded that excessively high speed generates problems such as an unstable deposition process and uneven size.

The effective widths of the deposited samples differed slightly, with the following order: \#15 s $>$ \#GRBC- $30 \mathrm{~cm} / \mathrm{min}-10 \mathrm{~s}>\# 5 \mathrm{~s}>\# 35 \mathrm{~cm} / \mathrm{min}>$ \#TRBC. The height difference was large, with the following order: \#15 s > \#GRBC- $30 \mathrm{~cm} / \mathrm{min}-10 \mathrm{~s}>\#$ TRBC $>\# 5 \mathrm{~s}>\# 35 \mathrm{~cm} / \mathrm{min}$. During single-path and multi-layer deposition, a previously deposited layer has a preheating effect on a subsequent deposited layer. Under the same wire feed speed, different heat inputs or wait times between layers affect the effective width and height. For both samples \#GRBC-30 cm $/ \mathrm{min}-10 \mathrm{~s}$ and \#TRBC, the sedimentary energy of the first layer was largest. For sample \#GRBC-30 cm/min-10 s, as the layers increased, the energy of each layer energy decreased incrementally until a heat balance (i.e., the heat absorption was equal to the heat loss) was achieved and each layer was deposited with fixed heat input. Therefore, the bottom roughness of sample \#TRBC was larger than that of sample \#GRBC- $30 \mathrm{~cm} / \mathrm{min}-10 \mathrm{~s}$ and the interlayer formation was uneven, as shown in Figure $5 b$.

The increased scanning speed employed for sample \#35 cm/min induced a decrease in the unit cladding quantity and deposition height. For sample \#5 s, the cooling time between layers was relatively short, and the thermal accumulation increased with increased layers. The spreadability of the liquid metal after welding was enhanced and the total sample height was reduced slightly. The effective width slightly exceeded that of sample \#15 s. However, the bottom formation of sample \#5 s was too wide and heat accumulation occurred at both ends; therefore, the formation appearance was poor and the deposition efficiency was decreased. For sample \#15 s, the deposition was slightly higher and the cooling time effect of the parent material at the bottom was prolonged. Hence, narrower molding was obtained in the first layer, which affected the effective width. The increased time reduced the deposition efficiency. Overall, the forming and efficiency of sample \#GRBC-30 cm/min-10 s were excellent compared to the other samples.

\subsection{Microstructure}

For the same voltage and current, different scanning speeds or cooling times have little influence on the weld depth at the sample bottom. In Figure 6a, the weld depth at the bottom of the deposited sample is relatively shallow. The cross-sectional metallographic images in Figure $6 \mathrm{~b}-\mathrm{d}$ reveals that the austenite dendrites contained reticulated ferrite. The cross-section center was composed of a large number of coarse columnar grains that grew upward in the main axis direction. These features were mainly due to the different heat dissipation conditions that the inner grains dissipated heat through the interlayers and grew upward and perpendicular to the interlayer remelting line. Comparing the 3rd and 7th layers, as shown in Figure $6 c$,d, the columnar crystals of sample \#GRBC- $30 \mathrm{~cm} / \mathrm{min}-10 \mathrm{~s}$ were coarser than those of sample \#TRBC. This difference was mainly due to the relatively large current at the bottom of sample \#GRBC- $30 \mathrm{~cm} / \mathrm{min}-10 \mathrm{~s}$. As shown in Figure $6 \mathrm{~b}$, the grain sizes in the 15 th layers of samples \#TRBC and \#GRBC- $30 \mathrm{~cm} / \mathrm{min}-10 \mathrm{~s}$ were similar. This was mainly because the current values after the 8th layer were all $60 \mathrm{~A}$, the heat input and heat dissipation in the central part of the sample reached thermal equilibrium, and the grains grew stably.

Figure $7 \mathrm{a}$ is a macrograph of the longitudinal section of the deposited sample \#GRBC-30 cm/min-10 s. The fusion lines between the layers are clearly visible, the layer height is uniform, and there are no obvious cracks, pores, or other macroscopic defects. As apparent from Figure $7 \mathrm{~b}$, the cladding of a subsequent layer induces crystal remelting of the previous layer, the specimen exhibits a columnar epitaxial growth formation overall [27]. The grain growth direction at the bottom of the longitudinal section differed from the vertical upward growth of the cross-section, but was consistent with the scanning direction, showing inclined, coarse, columnar-crystal staggered 
growth (indicated by red arrows in Figure 7b). The columnar crystals begin to grow vertically upward after the 5th layer. This behavior was mainly observed because the first few layers at the bottom dissipated heat through the base plate with a high cooling rate. However, the heat of the subsequent sediment layers mainly dissipated through the interlayer and air. The base plate had almost no effect on this behavior. Note that the heat input and heat dissipation of each layer were balanced. The heat dissipation direction was no longer affected by the scanning direction, and the grains grew vertically upward.
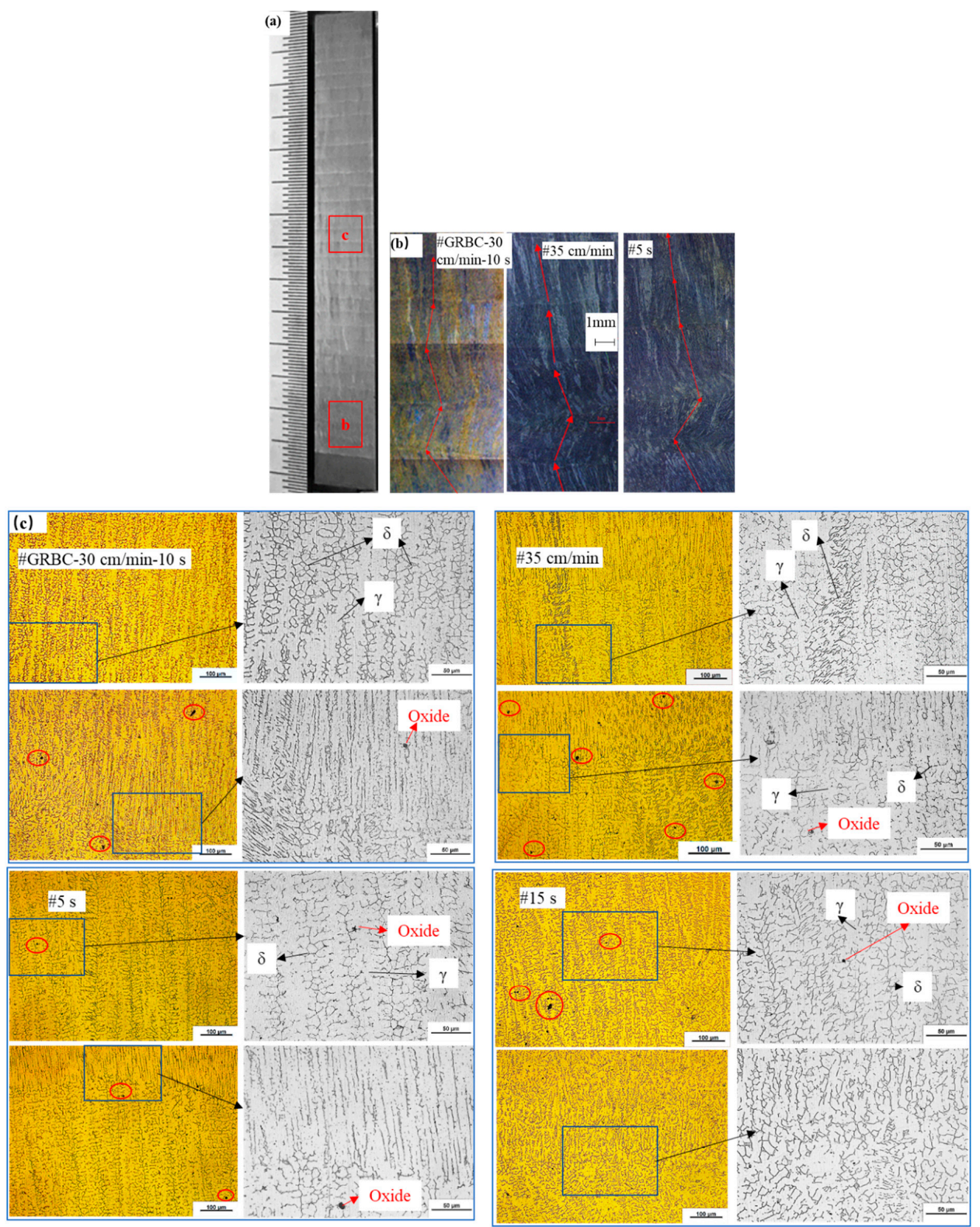

Figure 7. Longitudinal-section micrographs of 316L deposited samples: (a) Sample \#GRBC-30 $\mathrm{cm} / \mathrm{min}-10 \mathrm{~s} ;(\mathbf{b}, \mathbf{c})$ middle and bottom parts of different samples, respectively. (b,c) Correspond to the middle and bottom regions of (a), respectively. (TRBC and GRBC represent transient and gradual reduction of bottom current, respectively).

Austenite $(\gamma)$ and ferritic $(\delta)$ phases could be observed from the columnar dendritic structure in Figure 7c. According to the binary diagram of the microstructure, 316L tissue at room temperature is in the austenite equilibrium phase; however, the additive manufacturing process is characterized by a high-temperature gradient, high cooling rate, and repeated heating treatment, which allow easy 
production of a non-equilibrium phase [26,28]. As a result of the thermal influence of the subsequent layer on the previous layer, part of the ferrite is dissolved in the austenite and the remaining $\delta$ ferrite exhibits a vermicular shape [5,29], yielding the final formation of cellular or reticular austenite. This kind of columnar grain boundary is prone to cracking, which degrades the tensile strength. As shown in Figure 7c, compared with the grains size of samples, increasing the cooling time or scaning speed can refine the grain. Moreover, compared with the interlayer remelted peritectic, the heat accumulation decreased with prolonged cooling time. Thus, the remelted cellular crystals between the layers of sample \#15 s were relatively short, which can improve the vertical tensile property.

Note that some tiny oxides visible in Figure $7 \mathrm{c}$ were mainly caused by failed cleaning between layers. Secondly, as a result of the long tail of the molten pool generated by arc heating, the protective gas area moved in accordance with the scanning speed, resulting in oxidation of the exposed molten pool at high temperature. As the wait time was relatively long for sample \#15 s, the oxidation effect was prolonged. Although the wait time for sample $\# 35 \mathrm{~cm} / \mathrm{min}$ remained $10 \mathrm{~s}$, as a result of the increased scanning speed, the inter-layer wait time relative to the moving heat source was prolonged and the oxidation effect was strengthened. Therefore, there were more visible oxides when increasing speed or wait time.

In summary, gradual reduction of bottom current made the grain of bottom coarse, and increasing waiting time or scanning speed refined the grain and triggered more oxides. Moreover, increasing waiting time could also short the remelted cellular crystals between the layers.

\subsection{Microhardness}

The results obtained for the cross-section hardness test points of sample \#GRBC- $30 \mathrm{~cm} / \mathrm{min}-10 \mathrm{~s}$ are shown in Figure 8. The hardness curve is divided into upper, middle, and bottom parts. It is apparent that the hardness value decreased slowly from the bottom to top. The average hardness curves of each layer of the different samples' upper (layers 26-30), middle (layers 13-17), and bottom (layers 1-4) parts are shown in Figure 9. The overall trend of each sample curve is consistent with that of Figure 8. The hardness values of the middle layers were relatively stable in the range of 173.4-175.3 HV, because the heat input and heat dissipation achieved equilibrium. The average hardness at the bottom was in the range of 177.9-182.75 HV, which is slightly large. The average hardness at the top was 169-174.35 HV, which is slightly small. This result was mainly obtained because the heat accumulation affected the microhardness of the deposited samples. At room temperature, the bottoms of the samples close to the substrate could dissipate heat through the substrate during solidification and cooling. Thus, the cooling speed was higher than at the middle and upper parts. In addition, as several layers were deposited continuously above the bottom, the bottom sustained several transient thermal cycles with different heat amplitudes. Therefore, the bottom hardness was also slightly higher than that of the upper part.

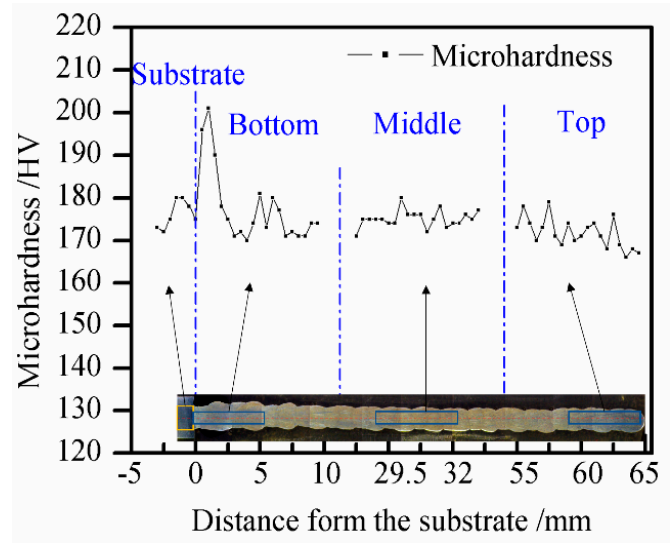

Figure 8. Microhardness profiles of different parts of sample \#GRBC-30 cm $/ \mathrm{min}-10 \mathrm{~s}$. 


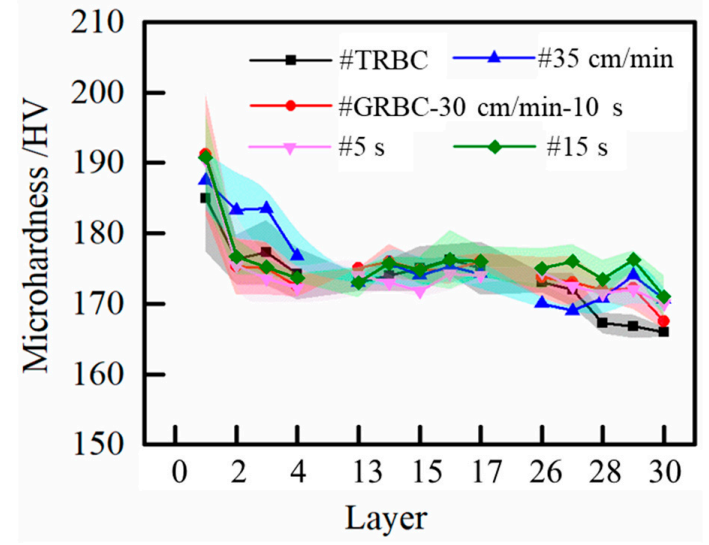

Figure 9. Microhardness curves measured on transverse sections of different layers of different samples. (TRBC and GRBC represent transient and gradual reduction of bottom current, respectively).

As shown in Figure 9, the hardness at the bottom of sample \#35 cm/min was $182.75 \mathrm{HV}$, which is relatively large. This may have been due to the rapid scanning speed and high cooling rate. As a result of the long cooling time, the upper-part hardness of sample \#15 s was also relatively large, at $174.35 \mathrm{HV}$. On the 3rd layer, the hardness of sample \#TRBC was $177.25 \mathrm{HV}$, being slightly greater than that of sample \#GRBC-30 cm /min-10 s (175 HV), since grains at the bottom of sample \#TRBC were more refined. This finding is consistent with the results presented in Figure 6.

The average microhardness values of the samples were calculated from 60 test points, as shown in Figure 10. Considering the error, the hardness value difference was not large and had the following order: \#15 s > \#35 cm/min > \#GRBC-30 cm/min-10 s > \#5 s > \#TRBC. As the cooling time was long or the scanning speed was fast, the thermal inputs of samples $\# 15 \mathrm{~s}$ and $\# 35 \mathrm{~cm} / \mathrm{min}$ were relatively small, yielding slightly higher hardness. In conclusion, the hardness parameters depend on the post treatment rather than the process parameters [4].

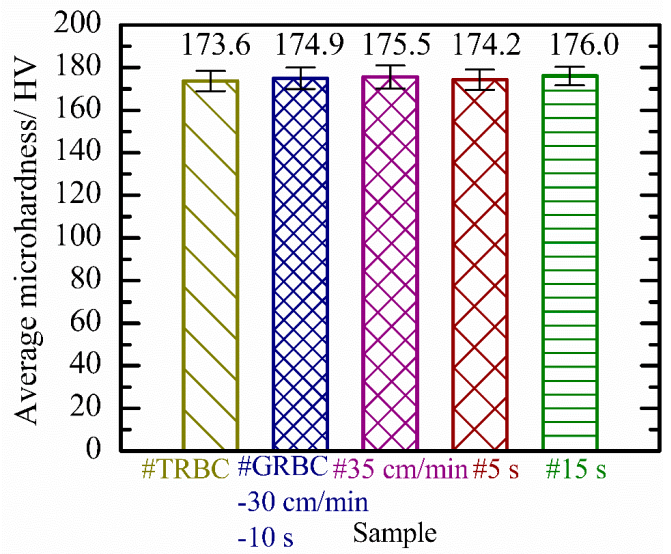

Figure 10. Average microhardness values of different samples. (TRBC and GRBC represent transient and gradual reduction of bottom current, respectively).

\subsection{Tensile Properties}

The tensile results for tensile specimens $\mathrm{H} 1-\mathrm{H} 3$ and $\mathrm{V} 1-\mathrm{V} 3$, as well as those for substrate tensile samples labeled BM1-BM3, are presented in Table 4. As the transient current mode was applied to the bottom of sample \#TRBC, unstable bottom formation and current jumps occurred, yielding uneven interlayer tissue and poor performance. Thus, the tensile strengths of \#TRBC-H2 and \#TRBC-H3 (i.e., the $\mathrm{H} 2$ and $\mathrm{H} 3$ specimens obtained from sample \#TRBC, respectively) were relatively small. 
Among all vertical tensile specimens of the deposited samples, V1 was superior to V2 and V3; this was mainly because V1 was close to the sample center. The previous stability analysis revealed that the edge shaping and stability were poor, and that the overall properties were relatively poor. The horizontal tensile strengths of the samples decreased from the bottom to the top, with order $\mathrm{H} 3>\mathrm{H} 2>$ $\mathrm{H} 1$, which is consistent with the hardness results. This behavior may have occurred because $\mathrm{H} 3$, at the bottom part, mainly exerts force on the grain boundaries between the columnar crystals growing vertically upward. However, staggered growth was observed for the crystal grains at the bottom, as shown in Figure $7 \mathrm{~b}$. Moreover, as a result of the rapid heat dissipation of the substrate and the high crystal cooling rate, the tensile strength and hardness were larger, and the overall properties were more satisfactory. In [15-17], the influence of the bottom material elements and forming were considered, while in [13] and [14], the unstable factors of the bottom forming were considered. In those studies, the bottoms were removed from the samples, reducing the DR. In the present study, the bottom of sample \#GRBC- $-30 \mathrm{~cm} / \mathrm{min}-10 \mathrm{~s}$ could be retained because its substrate was composed of the same material as the welding wire and, thus, the influence of different element mixing was avoided. Therefore, the DR was increased. The stress-displacement curves of \#GRBC- $30 \mathrm{~cm} / \mathrm{min}-10 \mathrm{~s}-\mathrm{H} 2$ and \#GRBC-30 $\mathrm{cm} / \mathrm{min}-10 \mathrm{~s}-\mathrm{V} 1$ are shown in Figure 11. The failure strain of \#GRBC- $30 \mathrm{~cm} / \mathrm{min}-10 \mathrm{~s}-\mathrm{V} 1$ and \#GRBC-30 $\mathrm{cm} / \mathrm{min}-10 \mathrm{~s}-\mathrm{H} 2$ were 0.57 and 0.7 , respectively. The results show that the strength and elongation rate of \#GRBC-30 cm $/ \mathrm{min}-10 \mathrm{~s}-\mathrm{H} 2$ are higher than those of \#GRBC-30 cm $/ \mathrm{min}-10 \mathrm{~s}-\mathrm{V} 1$.

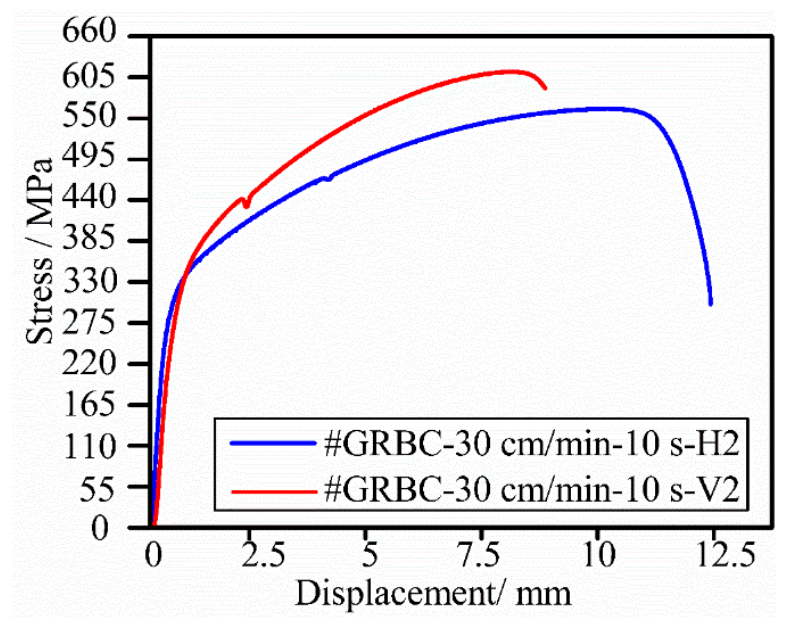

Figure 11. Stress-displacement curves of sample \#GRBC-30 cm/min-10 s (\#GRBC-30 cm/min-10 s-H2 and \#GRBC-30 cm/min-10 s-V1 represent the horizontal and vertical tensile specimens of sample \#GRBC-30 cm/min-10 s, respectively). (TRBC and GRBC represent transient and gradual reduction of bottom current, respectively). 
Table 4. Yield and ultimate strengths of tensile samples (BM represents substrate tensile sample, and TRBC and GRBC represent transient and gradual reduction of bottom current, respectively).

\begin{tabular}{|c|c|c|c|c|c|}
\hline Sample & $\begin{array}{l}\text { Yield Strength } \\
\text { (MPa) }\end{array}$ & $\begin{array}{l}\text { Ultimate Tensile } \\
\text { Strength (MPa) }\end{array}$ & Sample & $\begin{array}{l}\text { Yield'Strength } \\
\text { (MPa) }\end{array}$ & $\begin{array}{l}\text { Ultimate Tensile } \\
\text { Strength (MPa) }\end{array}$ \\
\hline \#TRBC-H1 & 335.00 & 537.40 & $\begin{array}{c}\text { \#GRBC-30 } \\
\mathrm{cm} / \mathrm{min}-10 \\
\mathrm{~s}-\mathrm{H} 1\end{array}$ & 330.17 & 541.08 \\
\hline \#TRBC-H2 & 310.00 & 498.77 & $\begin{array}{c}\text { \#GRBC-30 } \\
\mathrm{cm} / \mathrm{min}-10 \\
\mathrm{~s}-\mathrm{H} 2\end{array}$ & 345.67 & 561.38 \\
\hline \#TRBC-H3 & 336.83 & 563.78 & $\begin{array}{c}\text { \#GRBC-30 } \\
\mathrm{cm} / \mathrm{min}-10 \\
\mathrm{~s}-\mathrm{H} 3\end{array}$ & 327.17 & 570.56 \\
\hline \#TRBC-V1 & 370.33 & 628.19 & $\begin{array}{c}\text { \#GRBC-30 } \\
\mathrm{cm} / \mathrm{min}-10 \\
\mathrm{~s}-\mathrm{V} 1\end{array}$ & 369.17 & 628.04 \\
\hline \#TRBC-V2 & 371.11 & 616.07 & $\begin{array}{c}\text { \#GRBC-30 } \\
\mathrm{cm} / \mathrm{min}-10 \\
\mathrm{~s}-\mathrm{V} 2\end{array}$ & 364.17 & 606.68 \\
\hline \#TRBC-V3 & 342.56 & 585.83 & $\begin{array}{c}\text { \#GRBC-30 } \\
\mathrm{cm} / \mathrm{min}-10 \\
\mathrm{~s}-\mathrm{V} 3\end{array}$ & 339.50 & 574.68 \\
\hline $\begin{array}{c}\text { \#35 } \\
\mathrm{cm} / \mathrm{min}-\mathrm{H} 1\end{array}$ & 307.33 & 524.30 & $\# 5$ s-H1 & 307.00 & 551.39 \\
\hline $\begin{array}{c}\# 35 \\
\mathrm{~cm} / \mathrm{min}-\mathrm{H} 2\end{array}$ & 306.17 & 525.75 & $\# 5 \mathrm{~s}-\mathrm{H} 2$ & 325.63 & 567.09 \\
\hline $\begin{array}{c}\# 35 \\
\mathrm{~cm} / \mathrm{min}-\mathrm{H} 3\end{array}$ & 336.67 & 593.59 & $\# 5 \mathrm{~s}-\mathrm{H} 3$ & 330.17 & 584.99 \\
\hline$\# 35 \mathrm{~cm} / \mathrm{min}-\mathrm{V} 1$ & 359.56 & 634.47 & \#5 s-V1 & 329.17 & 600.53 \\
\hline$\# 35 \mathrm{~cm} / \mathrm{min}-\mathrm{V} 2$ & 336.67 & 602.56 & $\# 5 \mathrm{~s}-\mathrm{V} 2$ & 323.00 & 579.75 \\
\hline$\# 35 \mathrm{~cm} / \mathrm{min}-\mathrm{V} 3$ & 336.67 & 621.44 & $\# 5 \mathrm{~s}-\mathrm{V} 3$ & 329.17 & 589.26 \\
\hline \#15 s-H1 & 333.33 & 564.69 & BM1 & 383.33 & 641.24 \\
\hline$\# 15$ s-H2 & 335.83 & 558.86 & BM2 & 380.21 & 651.78 \\
\hline \#15 s-H3 & 353.00 & 619.28 & BM3 & 385.85 & 630.59 \\
\hline \#15 s-V1 & 373.00 & 637.98 & - & - & - \\
\hline$\# 15$ s-V2 & 345.83 & 609.24 & - & - & - \\
\hline \#15 s-V3 & 365.50 & 595.88 & - & - & - \\
\hline
\end{tabular}

The average yield strengths and ultimate tensile strengths of the $\mathrm{H} 1-\mathrm{H} 3$ and V1-V3 specimens of each deposited sample are shown in Figure 12. The mean values did not differ largely between samples, but the horizontal and vertical tensile strengths of the same deposited sample did differ. These properties are mainly determined by the deposition direction, which causes upward growth of the coarse columnar crystals leading to anisotropy [30,31].

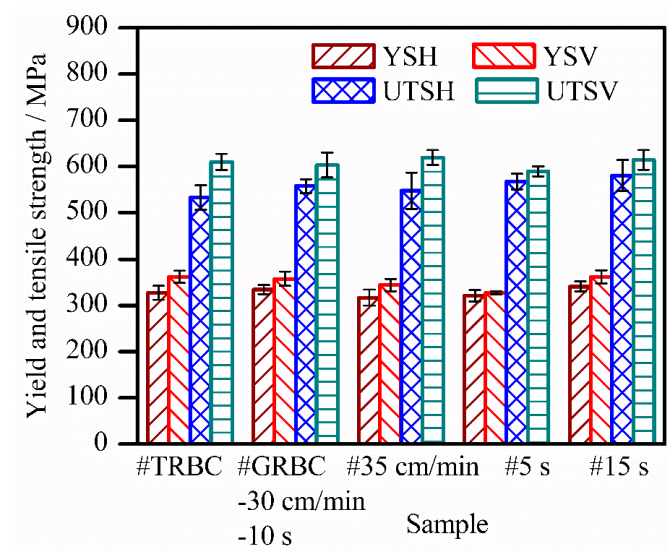

Figure 12. Horizontal and vertical yield and tensile strengths of different samples. (TRBC and GRBC represent transient and gradual reduction of bottom current, respectively). 
Horizontal stretching mainly resists the boundary forces between grains, while vertical stretching mainly resists the forces inside the grains and between the layers. In the specimens examined in this study, the vertical tensile strengths exceeded the horizontal tensile strengths. This finding indicates that the interlaminar combination was relatively good and that the forces inside the grains exceeded the grain boundary forces.

As anisotropy affects the properties of additive manufacturing samples, the degree of anisotropy was calculated using the following Equation [32]:

$$
p=\frac{P_{\max }-P_{\min }}{P_{\max }} \times 100 \%
$$

where $A p$ represents the anisotropic percentage, $P_{\max }$ and $P_{\min }$ represent the maximum and minimum strengths of the horizontal or vertical samples, respectively.

The anisotropic percentages of the yield and ultimate tensile strengths of each sample were obtained from Equation (5), as shown in the histogram of Figure 13. The anisotropy of sample \#5 $\mathrm{s}$ was minimal, mainly because of the short heat dissipation time, severe heat accumulation, and cooling rate decline of that sample. Compared with the other samples, the preheating effect of the previous layers on the subsequent layers was enhanced, and the post-heat treatment effect of the subsequent layers on the previous layers was also strengthened. Hence, the structure was more uniform, and the horizontal and vertical performances were more similar than those of the other specimens [33]. A higher scanning speed was employed for sample $\# 35 \mathrm{~cm} / \mathrm{min}$, which accelerated the cooling rate; thus, the anisotropy was relatively obvious, and up to $11.56 \%$. Because of the relatively low thermal input of the bottom transient current (sample \#TRBC), the anisotropy was more pronounced. In this study, the parameter variation had little effect on the columnar crystal structure, which may have affected the interlaminar binding force and the strength between grain boundaries. Further study of this aspect is required.

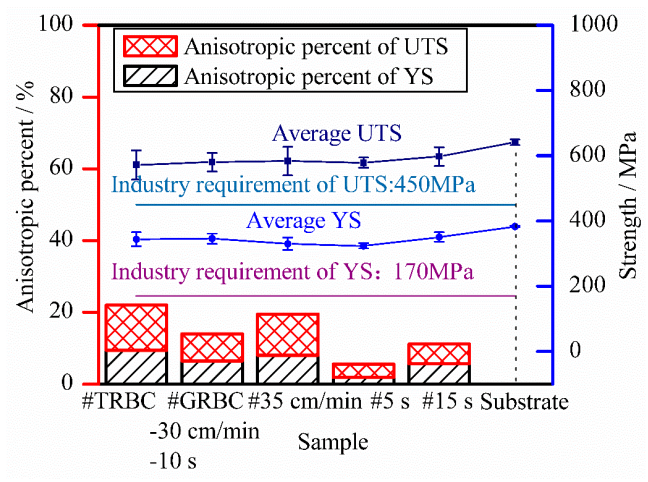

Figure 13. Anisotropic percentage and average of horizontal and vertical ultimate tensile strengths (UTSH and UTSV, respectively), and horizontal and vertical yield strengths (YSH and YSV, respectively) of different samples. (TRBC and GRBC represent transient and gradual reduction of bottom current, respectively).

As shown in Figure 13, because of the lower heat input and finer grain, the average yield strength and ultimate tensile strength of sample \#35 cm/ min and sample \#15 s were higher than those other samples, while the value of sample \#5 s was smaller for its coarse grain. These results are consistent with the hardness values analyzed in Figure 10.

The average values of all samples were approximately 339 and $583 \mathrm{MPa}$ for yield strength and ultimate tensile strength, respectively. These values are higher than the industrial forging standards (170 and $450 \mathrm{MPa}$, respectively) [34], and slightly lower than the average values for the substrate of 383.13 and $641.2 \mathrm{MPa}$, respectively. As regards other manufacturing methods, the internal structure of forged 316L is austenite equiaxed crystal, while that of additive manufactured 316 $\mathrm{L}$ is mainly austenite columnar crystal. Although the structures differ, the tensile strength of additive manufactured 316L 
is higher than that obtained for casted (552 MPa) and hot-rolled (480 MPa) 316L [35]. Therefore, although the tensile strengths of the 316L deposited samples obtained using MIG arc welding exhibited anisotropy, the lowest value satisfied industrial requirements.

Because the tensile properties of samples \#TRBC and \#GRBC-30 cm/min-10 s were similar, the fracture morphologies of samples \#GRBC-30 cm/min-10 s, \#35 cm/min, \#5 s, and \#15 s only were examined. From the macro fractures obtained in small pictures of Figure 14, it is apparent that the fractures all had gray-fiber shapes. Furthermore, the thickness and width directions of the fractures of the horizontal tensile samples indicated obvious shrinkage in the stretching process; that is, the cross-section shrinkage of the horizontal tensile samples was larger than that of the vertical tensile samples. This indicates that the plasticity of horizontal tensile samples is better than that of vertical ones, which is corresponding with the result of Figure 11.

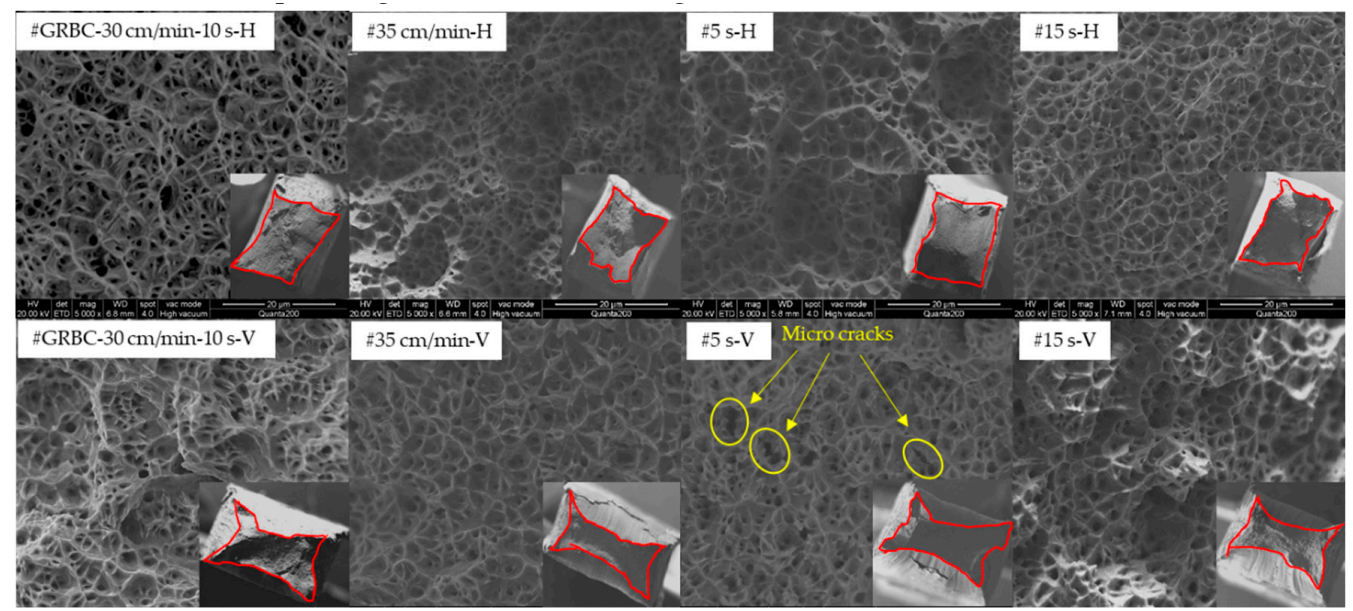

Figure 14. Macroscopic and microscopic fracture surfaces of MIG-AM 316L samples (\#GRBC-30 $\mathrm{cm} / \mathrm{min}-10 \mathrm{~s}-\mathrm{H}$ and \#GRBC-30 cm $/ \mathrm{min}-10 \mathrm{~s}-\mathrm{V}$ represent the horizontal and vertical tensile fracture surfaces of sample \#GRBC-30 cm/min-10 s, respectively). (TRBC and GRBC represent transient and gradual reduction of bottom current, respectively).

The microscopic morphologies of the tensile fractures of the deposited samples were analyzed via SEM, as shown in Figure 14. A large number of equiaxed dimples were apparent in the fractures of all specimens. In the tensile process, the stress was uniformly distributed on the entire fracture surface and the micropores grew uniformly in three directions, forming equiaxial dimples. Multi-scale dimples occurred. Furthermore, tearing edges were obvious around the dimples, indicating that the plastic deformation was sufficient. Overall, the fracture analysis revealed the characteristics of typical polymerizable dimple ductile fracturing. This result is related to the size of the macroscopic fracture contraction surface, and further indicates that the horizontal tensile samples had superior plasticity.

For the horizontal tensile fractures, changes in scanning speed had little effect on the dimples. In addition, the longer cooling time of sample \#GRBC-30 cm/min-10 s and sample \#15 s yielded big and deep dimples. Thus, more energy was required for the fractures to break the micropore boundaries and the horizontal tensile strength of sample \#GRBC-30 cm/min-10 s and sample \#15 s was relatively large [36]. As regards the vertical tensile fractures, microcracks (secondary cracks) could be seen in the fracture of sample \#5 s. It is possible that the stretching process induced rapid fracturing as a result of the short cooling time and severe heat accumulation, and no sufficient plastic deformation was obtained. Hence, the sample performance was degraded. This is consistent with the tensile strength result.

The tensile sample contained 1.5 to 2 layers approximately, which means the columnar crystals and interlayer remelted peritectic crystals could be included in tensile samples. Therefore, the results of tensile could reflect the strength of the grain boundary force and interlayer binding force. The relationships between the tensile load direction and the growth directions of the columnar crystals 
and interlayer remelted peritectic crystals are shown in Figure 15a,b, respectively. The horizontal stretching exerted a transverse force on the boundaries of the columnar crystals and remelted peritectic crystals, while vertical tension was generated along the growth direction of the columnar crystals and the interlayer remelted crystal (macroscopically, the interlayer binding force). The cracks in the metal expanded along the region with the minimum energy consumption. This indicates that the tensile strength inside the grains derived from the growth direction exceeded that between the grain boundaries. The interlayer remelted peritectic crystals improved the interlayer bonding ability. Compared with the vertical stretch samples, the horizontal stretch samples contained more grain boundaries. During the deposition process, the grain-boundary binding force and strength would have been weakened. Therefore, low stress occurred along the grain fractures, and the tensile load of the horizontal direction was applied more strongly at the grain boundaries, causing anisotropy of the deposited samples. In future research, to improve the uniformity of the mechanical properties, the growth direction of the columnar crystals should be changed or the column crystals should be broken and refined.

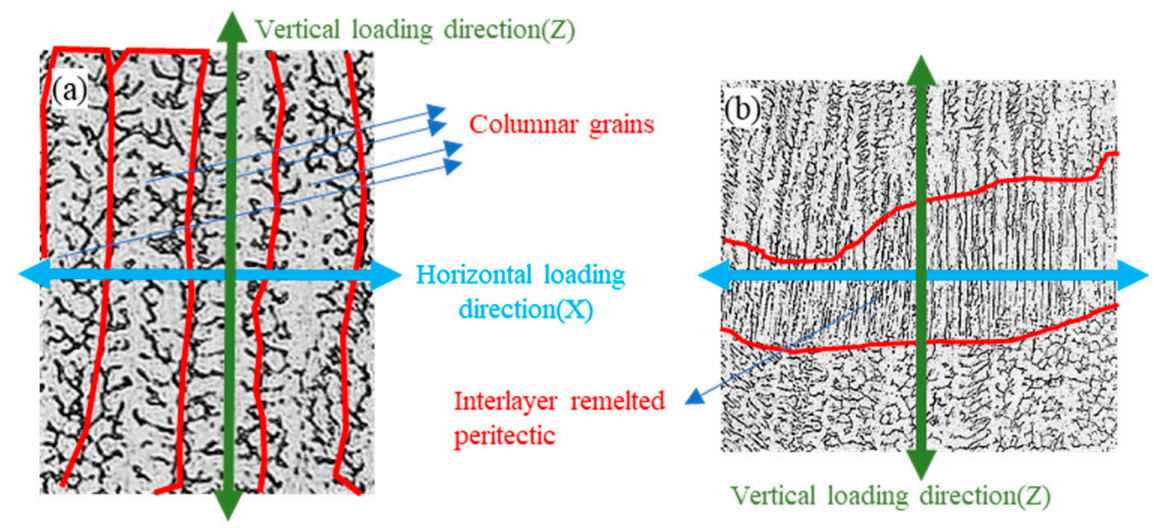

Figure 15. Relationships between tensile loading and: (a) columnar grain; and (b) interlayer remelted peritectic growth directions.

\section{Conclusions}

This study investigated the speed cold welding additive manufacturing method for 316L stainless steel using $0.8 \mathrm{~mm}$ wire, and analyzed the influence of different technical parameters on deposition process stability, morphology, microstructure, and performance. The analysis results are as follows:

(1) The probability density curves of current and voltage can well reflect the stability of deposition process. The areas of sample \#GRBC-30 cm/min-10 s with fewer dispersion values are relatively narrower than other samples in those curves, which indicates more stable during deposition process.

(2) Gradually and transiently decreasing current modes strongly influence the bottom formation and performance. Although a gradual current decrease makes the bottom grain coarse, but yields stable formation after the third layer, and the deposition bottom formation and performance are relatively good.

(3) Increasing the scanning speed or shortening the cooling time can increase the surface roughness and decrease the effective deposition efficiency. The hardness and tensile strength increase slightly with high scanning speed or long cooling time for their refined grains. However, the anisotropy percentage of tensile strength for high speed was as high as $11.56 \%$.

(4) The hardness is mainly determined by the heat effect. As the high cooling rate and latter layers' heat effect acted on the bottom part, the bottom hardness and tensile strength were slightly higher than those of the middle and upper parts of the deposited samples. Moreover, the staggered columnar crystals enhanced the tensile strength of bottom part.

(5) The average hardness and ultimate tensile strength were approximately $174.6 \mathrm{HV}$ and $583 \mathrm{MPa}$, respectively. Depositions by MIG welding have high anisotropic percentage in tensile strength, which 
ranging from $3.73 \%$ to $12.58 \%$ for different samples. The vertical ultimate tensile strengths ranged from 589.8 to $619.49 \mathrm{MPa}$, and the toughness was superior to that of the horizontal ones, which was 533.3-580.9 MPa.

In the future, further optimization of the arc initiation and termination points is required. In addition, the double-wire additive manufacturing method can be used to increase the deposition efficiency. To further resolve the anisotropy caused by the coarse columnar crystals in the deposition direction, human intervention can be adopted as the next step to refine the grains and reduce the anisotropy, so as to optimize the material performance.

Author Contributions: Methodology, W.W., J.X. and L.W.; writing-original draft preparation, W.W. and L.W.; project administration and funding acquisition, J.X.; data curation, W.W. and Z.Z.; writing — review and editing, providing ideas, Y.H. and C.D.

Funding: This paper was supported by the National Natural Science Foundation Project of China (51875213) and the High-Level Leading Talent Introduction Program of Guangdong Academy of Sciences (grant number 2016-GDASRC-0106); and the Natural Science Foundation of Fujian Province (grant numbers 2018J01503), Longyan Science and Technology Project (grant number 2017LY68).

Conflicts of Interest: The authors declare no conflicts of interest.

\section{References}

1. Cunningham, C.R.; WikshLand, S.; Xu, F.; Kemakolam, N.; Shokrani, A.; Dhokia, V. Cost modelling and sensitivity analysis of wire and arc additive manufacturing. Procedia Manuf. 2017, 11, 650-657. [CrossRef]

2. Williams, S.W.; Martina, F.; Addison, A.C.; Ding, J.; Pardal, G.; Colegrove, P. Wire + arc additive manufacturing. Mater. Sci. Technol. 2016, 7, 641-647. [CrossRef]

3. Jhavar, S.; Jain, N.K.; Paul, C.P. Development of micro-plasma transferred arc ( $\mu$-PTA) wire deposition process for additive layer manufacturing applications. J. Mater. Process. Technol. 2014, 214, 1102-1110. [CrossRef]

4. Ding, D.; Pan, Z.; Cuiuri, D.; Li, H. Wire-feed additive manufacturing of metal components: Technologies, developments and future interests. Int. J. Adv. Manuf. Technol. 2015, 81, 465-481. [CrossRef]

5. Xu, X.; Mi, G.; Luo, Y.; Jiang, P.; Shao, X.; Wang, C. Morphologies, microstructures, and mechanical properties of samples produced using laser metal deposition with 316L stainless steel wire. Opt. Lasers Eng. 2017, 94, 1-11. [CrossRef]

6. Yang, D.; Wang, G.; Zhang, G. Thermal analysis for single-pass multi-layer GMAW based additive manufacturing using infrared thermography. J. Mater. Process. Technol. 2017, 244, 215-224. [CrossRef]

7. Zhang, Y.M.; Chen, Y.; Li, P.; Male, A.T. Weld deposition-based rapid prototyping: A preliminary study. J. Mater. Process. Technol. 2003, 135, 347-357. [CrossRef]

8. Jiang, Y.L. Research on the Rapid Prototyping Technology and Forming Process of Aluminum Alloy Based on the CMT. Master's Thesis, Harbin Institute of Technology, Harbin, China, 2013.

9. Xiong, J. Forming Characteristics in Multi-Layer Single-Bead GMA Additive Manufacturing and Control for Deposition Dimension. Master's Thesis, Harbin Institute of Technology, Harbin, China, 2014.

10. Xiong, J.; Li, Y.; Li, R.; Yin, Z. Influences of process parameters on surface roughness of multi-layer single-pass thin-walled parts in GMAW-based additive manufacturing. J. Mater. Process. Technol. 2018, 252, 128-136. [CrossRef]

11. Wei, F.U.; Shengsun, H.U.; Yuhuan, Y. Effect of droplet transition on rapid prototyping by P-MIG. J. Mech. Eng. 2009, 45, 95-99.

12. Montevecchi, F.; Venturini, G.; Grossi, N.; Scippa, A.; Campatelli, G. Idle times selection for wire arc additive manufacturing: A finite element based technique. Addit. Manuf. 2018, 21, 479-486. [CrossRef]

13. Wu, Q.; Ma, Z.; Chen, G.; Liu, C.; Ma, D.; Ma, S. Obtaining fine microstructure and unsupported overhangs by low heat input pulse arc additive manufacturing. J. Manuf. Process. 2017, 27, 198-206. [CrossRef]

14. Martina, F.; Mehnen, J.; Williams, S.W.; Colegrove, P.; Wang, F. Investigation of the benefits of plasma deposition for the additive layer manufacture of Ti-6Al-4V. J. Mater. Process. Technol. 2012, 212, 1377-1386. [CrossRef] 
15. Shen, C.; Pan, Z.; Cuiuri, D.; Dong, B.; Li, H. In-depth study of the mechanical properties for $\mathrm{Fe}_{3} \mathrm{Al}$ based iron aluminide fabricated using the wire-arc additive manufacturing process. Mater. Sci. Eng. A 2016, 669, 118-126. [CrossRef]

16. Shen, C.; Liss, K.D.; Pan, Z.; Wang, Z.; Li, X.; Li, H. Thermal cycling of $\mathrm{Fe}_{3} \mathrm{Al}$ based iron aluminide during the wire-arc additive manufacturing process: An in-situ neutron diffraction study. Intermetallics 2018, 92, 101-107. [CrossRef]

17. Xu, X.; Ganguly, S.; Ding, J.; Guo, S.; Williams, S.; Martina, F. Microstructural evolution and mechanical properties of maraging steel produced by wire + arc additive manufacture process. Mater. Charact. 2017, 1-11. [CrossRef]

18. Demir, A.G. Micro laser metal wire deposition for additive manufacturing of thin-walled structures. Opt. Lasers Eng. 2018, 100, 9-17. [CrossRef]

19. Cong, B.; Ding, J.; Williams, S. Effect of arc mode in cold metal transfer process on porosity of additively manufactured Al-6.3\%Cu alloy. Int. J. Adv. Manuf. Technol. 2015, 76, 1593-1606. [CrossRef]

20. Gomez Ortega, A.; Corona Galvan, L.; Deschaux-Beaume, F.; Mezrag, B.; Rouquette, S. Effect of process parameters on the quality of aluminium alloy $\mathrm{Al}_{5} \mathrm{Si}$ deposits in wire and arc additive manufacturing using a cold metal transfer process. Sci. Technol. Weld. Join. 2017, 23, 316-332. [CrossRef]

21. Gu, J.; Ding, J.; Williams, S.W.; Gu, H.; Ma, P.; Zhai, Y. The effect of inter-layer cold working and post-deposition heat treatment on porosity in additively manufactured aluminum alloys. J. Mater. Process. Technol. 2016, 230, 26-34. [CrossRef]

22. Li, F.; Chen, S.; Shi, J.; Zhao, Y.; Tian, H. Thermoelectric cooling-aided bead geometry regulation in wire and arc-based additive manufacturing of thin-walled structures. Appl. Sci. 2018, 8, 207. [CrossRef]

23. Wang, H.; Jiang, W.; Ouyang, J.; Kovacevic, R. Rapid prototyping of 4043 Al-alloy parts by VP-GTAW. J. Mater. Process. Technol. 2004, 148, 93-102. [CrossRef]

24. Li, J.; Li, H.; Huang, C.; Xiang, T.; Ni, Y.; Wei, H. Welding process characteristics of pulse on pulse MIG arc brazing of aluminum alloy to stainless steel. Int. J. Adv. Manuf. Technol. 2016, 91, 1057-1067. [CrossRef]

25. Guo, N.; Guo, W.; Xu, C.S.; Du, Y.P.; Feng, J.C. Effect of boric acid concentration on the arc stability in underwater wet welding. J. Mater. Process. Technol. 2016, 229, 244-252. [CrossRef]

26. Sequeira Almeida, P.M. Process control and development in wire and arc additive manufacturing. Cranfield Univ. 2012, 30, 218-226. [CrossRef]

27. Lin, X.; Huang, W.D. Laser additive manufacturing of high-performance metal components. Sci. Sin. 2015, 45, 1111-1126. [CrossRef]

28. Liberini, M.; Astarita, A.; Campatelli, G.; Scippa, A.; Montevecchi, F.; Venturini, G. Selection of optimal process parameters for wire arc additive manufacturing. Procedia Cirp 2017, 62, 470-474. [CrossRef]

29. Geng, H.; Li, J.; Xiong, J.; Lin, X.; Zhang, F. Geometric limitation and tensile properties of wire and arc additive manufacturing 5A06 aluminum alloy parts. J. Mater. Eng. Perform. 2017, 26, 621-629. [CrossRef]

30. Wang, P.; Sharon Nai, M.L.; Tan, X.; Sin, W.J.; Tor, S.B.; Wei, J. Anisotropic Mechanical Properties in a Big-Sized Ti-6Al-4V Plate Fabricated by Electron Beam Melting. In TMS 2016 145th Annual Meeting $\mathcal{E}$ Exhibition; Springer International Publishing: Cham, Switzerland, 2016; pp. 5-12.

31. Cain, V.; Thijs, L.; Van Humbeeck, J.; Van Hooreweder, B.; Knutsen, R. Crack propagation and fracture toughness of Ti6Al4V alloy produced by selective laser melting. Addit. Manuf. 2015, 5, 68-76. [CrossRef]

32. Alcisto, J.; Enriquez, A.; Garcia, H.; Hinkson, S.; Steelman, T.; Silverman, E. Tensile properties and microstructures of laser-formed Ti-6Al-4V. J. Mater. Eng. Perform. 2011, 20, 203-212. [CrossRef]

33. Wang, T.; Zhang, Y.; Wu, Z.; Shi, C. Microstructure and properties of die steel fabricated by WAAM using H13 wire. Vacuum 2018, 149, 185-189. [CrossRef]

34. Standard Specification for Stainless Steel Forgings; 100 Barr Harbor Drive; ASTM: West Conshohocken, PA, USA, 2015. 
35. Villanueva, D.M.; Junior, F.C.; Plaut, R.L.; Padilha, A.F. Comparative study on sigma phase precipitation of three types of stainless steels: Austenitic, superferritic and duplex. Met. Sci. J. 2006, 22, 1098-1104. [CrossRef]

36. Zhong, Y.; Rännar, L.; Liu, L.; Koptyug, A.; Wikman, S.; Olsen, J. Additive manufacturing of 316L stainless steel by electron beam melting for nuclear fusion applications. J. Nucl. Mater. 2017, 486, 234-245. [CrossRef]

(c) 2019 by the authors. Licensee MDPI, Basel, Switzerland. This article is an open access article distributed under the terms and conditions of the Creative Commons Attribution (CC BY) license (http:// creativecommons.org/licenses/by/4.0/). 